\title{
Metastable Nanosized Diamond Formation from Fluid Phase
}

\author{
Sergei K. Simakov ${ }^{1}$, Viktor T. Dubinchuk ${ }^{2}$, Mikhail P. Novikov ${ }^{3}$, Nikolai N. Melnik $^{4}$ \\ ${ }^{1}$ Geological Department, St.Petersburg University, 7/9 Universitetskaya Nab., St.Petersburg, \\ 199034, Russia \\ ${ }^{2}$ Fedorovskiy All Russian Mineral Research Institute, 119017 Moscow, Russia \\ ${ }^{3}$ Institute of Experimental Mineralogy, Russian Academy of Sciences, 142432 Chernogolovka, \\ Russia \\ ${ }^{4}$ Lebedev Physics Institute, Russian Academy of Sciences, 117924 Moscow, Russia
}

The formation of the bulk of Earth diamonds is due to the deep upper mantle rocks formed at $\mathrm{P}$ and $\mathrm{T}$ corresponded to diamond thermodynamic stability. Meanwhile there is evidence that part of kimberlitic diamonds (with size less than $1 \mathrm{~mm}$ ) was formed at lower P-T parameters corresponding to graphite stability, probably caused by introduction of metasomatic fluids (Spetsius, 1999). Microdiamonds were also discovered in ultramafic rocks of Kamchatka (Shilo et al., 1979) and in vulcanoclastic komatiite of French Guiana (Capdivela et al., 2003). Nanocrystalline diamonds were found in garnet pyroxenite xenoliths of Hawaiyan and Gissar basaltes (Wirth. and Rocholl, 2003; Novgorodova. and Rasskazov, 1992). From another side over the last 35 years microdiamonds have also been founded in the different crustal rocks (Novgorodova et al., 1984; Rozen et al., 1976; Xu et al., 1992). The most famous and important deposit of crustal diamonds is Kokchetave massive situated in Northern Kazakhstan (Sobolev and Shatsky, 1990). In this complex the diamonds mainly associate with graphite and the main mineral diamond inclusions are graphite, carbonate and water (De Corte et al., 1999).

Kokchetave diamonds have anomaly high concentration of $\mathrm{N}$ in comparing with kimberlitic ((De Corte et al., 1999). Nitrogen could intrude in to the diamond structure according to reaction for ammonium distraction and stabilize the diamond nucleus formation (Sobolev et al., 1966; Simakov, 1984) The stabilized role of nitrogen for Earth diamonds can be explained by the facts that $\mathrm{N}$ is the main crystallo-chemical mixture in natural diamonds (Kaiser and Bond, 1959). From another hand stabilised role of nitrogen at the diamond syntheses known from experiments (Hannay, 1880). It's known crystallization in a P-T regime where diamond is actually thermodynamically unstable with respect to graphite. It's possible due to kinetic factors and seeds of the required phase or a substrate which allows epitaxial overgrowth. Deryagin and Fedoseev (1977) have shown that diamonds can grow from methane-rich fluid at metastable P-T conditions on the seeds. From another side in (Korsakov and Shatsky, 2004) was shown that Kokchetave graphite and diamond have formed from one fluid source.

On the basis of these data we came to the conclusion that nitrogen could be used for the metastable diamond formation from carbon-bearing gases without the use of a seeds. We provided the synthesis of free carbon from carbon-bearing gases at $500^{\circ} \mathrm{C}$ and total pressure of $1000 \mathrm{~atm}$ in titanium autoclaves (BT-8 alloy). The source of carbon-bearing gases was organic matters with the presence of nitrogen. Metallic iron served as an oxygen buffer. The run duration was 5-7 days. Using X-ray diffraction method in the experimental products nanographite was identified (Simakov et al., 2004). Raman and photoluminescence (PL) spectra were recorded on a U-1000 spectrometer with the microscope setup. Argon laser radiation (488 nm) was used for excitation. The laser exciting radiation was focused to a spot in $\sim 10 \mathrm{mkm}$ diameter. This allowed us to study the homogeneous and transition areas of the sample surface and monitor the absence of laser heating effect on the sample. The Raman spectra were recorded with a resolution of $1-5 \mathrm{~cm}^{-1}$. The samples were studied by Raman scattering (RS). The resultes of the analyses are shown on Fig 1. The curve 1 is RS of opaque samples. From the form of a spectrum obviously, that these samples are strongly disordered graphite. But there are samples (after clearing by solvent), which have white coloring. Their typical RS spectrum is submitted to a curve 2. In Fig.1 are submitted RS spectra of diamond (D) and disordered graphite $(\mathrm{G})$ for comparison. Comparing these spectra it is possible to draw a conclusion, that the cleared samples contain atoms of carbon with $s p^{3}$ bonds. With a high probability it there can be micro particles of diamond. The nature of wide bands in region $1120 \div 1300 \mathrm{~cm}^{-1}$ is not clear yet and demands the further studying. After this, the products were treated in concentrated $\mathrm{HClO}_{4}$ to remove graphite. The powder that remained after washing was loaded in colloidal solution in amyl acetate and then applied on the water surface. The film obtained was transferred onto a grid 
for electron microscopic investigation. Samples were studied with a Tecnai-12 electron microscope at an accelerating voltage of $120 \mathrm{kV}$ with using camera "Gotana". The carrier film universally contains 70-80 nm-sized particles of different forms (Fig. 2). Diamonds were diagnosed in the particles by microdiffraction method. Microdiffractions corresponding to diamond Interplanar spacings determined from Fig.2a,b coincide with those for diamond $\left(\mathrm{a}=3,55 \mathrm{~A}^{\circ}\right)$ presented in the ASTM database (card 06-0675) - Table 1 and correspond to Fd3m spacing group. None of the known cubic phases have such interplanar spacings in ASTM. In another particles graphite, chaoite, cubic carbon, carbides and lonsdaleite were diagnosed by the same method (Simakov et al., 2004; 2007).

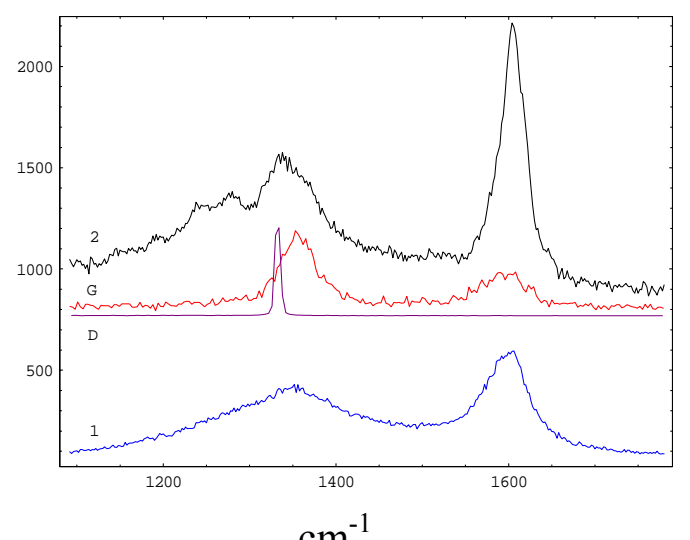

Figure 1. RS spectra of different samples. 1 - opaque samples; 2 - white coloring samples; D - diamond; G graphite.
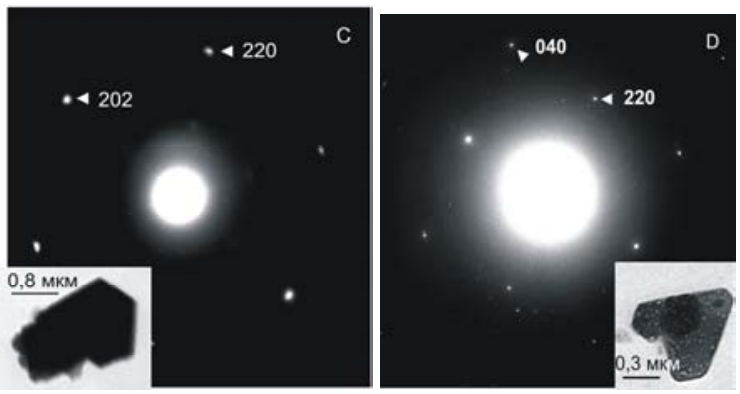

Figure 2. Microdifractions and form of the diamond, zone axis's [111] and [001] correspondingly.

\begin{tabular}{|l|l|l|}
\hline \multicolumn{1}{|c|}{$H \mathrm{Hkl}$} & ASTM & $d_{\text {calc. }} A$ \\
\hline & diamond & \\
\hline$<220>$ & 1,26 & 1,26 \\
\hline 220 & 1,26 & 1,26 \\
\hline 040 & 0,88 & 0,88 \\
\hline
\end{tabular}

Table 1. Comparison of interplanar spacings based on the microdiffraction pattern in Fig. 2 with data on diamond presented in the ASTM database (card 060675).
We also provided the same experiments without nitrogen presence. In them diamond and diamondlike phases were absent.

Thus the resultes indicate that diamond and diamond-like phases could be formed from carbonbearing fluids at low temperatures and pressures without diamond or another seeds. The presence of nitrogen can stabylize diamond formation at metastable parameters. From it follows that microdiamonds could be formed from fluids in crustal and magmatic rocks at $\mathrm{P}-\mathrm{T}$ parameters corresponding to graphite stability.

\section{References}

Capdivela, R., Arndt, N., Letendre, J., Savage, J.-F. 1999. Diamonds in volcanoclastic komatiite from French Guiana. Nature 399, 456-458.

De Corte, K., Cartigny, P., Shatsky, V.S., De Paepe, P., Sobolev, M.V., Javoy, M. 1999 Characteristics of microdiamond from UHPM rocks of the Kokchetav massif (Kazakhstan). In: Gurney, J.J., Gurney, L.G., Pascoe, M.D., Richardson, S.H (Eds.) Proceedings of the VIIth International Kimberlite Confertence. Cape Town. 2, 174-182.

Deryagin, B.V., Fedoseev, D.V. 1977. Growth of diamond and graphite from the gas phase. Nauka, Moscow. 115 p. (in Rusian)

Hannay, J.B.1880. On the artificial formation of the diamond. Proceedings of Royal Society. 30, 450-461.

Kaiser, W., Bond, W.L. 1959. Nitrogen - a major impurity in common type 1 diamond. Physical Review. $115,857-863$.

Korsakov, A.V., Shatsky, V.S. 2004. Origin of Graphite-Coated Diamonds from Ultrahigh-Pressure Metamorphic Rocks. Doklady Earth Sciences. 399A, 1160-1163.

Novgorodova, M.I., Usupov, R.G., Dmitrieva, M.T. 1984. Cubic carbide of silicium in the integrowing with graphite and diamond from mumie. Doklady Akademii Nauk SSSR. 277, 1222-1227. (in Rusian)

Novgorodova, M.I., Rasskazov, A.V. 1992. Highpressure carbon mineral phase formation as a result of heat explosion at shift transformation of graphite. Doklady Akademii Nauk SSSR. 322, 379-381. (in Rusian)

Rozen, O.M., Zorin, U.M., Zayachkovsky, A.A. 1972. Diamond foundation in connection of precembrian eclogites of Kokchetave massive. Doklady Akademii Nauk SSSR. 203, 674-676.

Shilo, N.A., Kaminsky, F.V., Lavrova, L.D., Dolmatov, B.K., Pleshakov, A.P., Tkachenko, L.A., Shepeleva, K.A. 1979. First foundation of diamond in ultramafic rocks of Kamchatka. Doklady Akademii Nauk SSSR. 248, 1211-1214.

Simakov, S.K. 1984. Possibility of metastable diamond formation from fluids in continental crust conditions. Doklady Akademii Nauk SSSR. 278, 953-957.

Simakov, S.K., Kalmykov, A.E., Sorokin, L.M., Novikov, M.P., Drozdova, I.A., Yagovkina, M.A., Grebenshchikova, E.A. 2004. Chaoite formation from 
carbon-bearing fluid at low PT parameters. Dokl. Earth Scie., 399A, 1289-1290.

Simakov, S.K., Dubinchuk, V.T., Baidakova, M.V. 2007. Synthesis of nanosize diamond and diamondlike phases at lower temperatures and pressures. NDNC2007 Abstract Book. 279.

Sobolev, E.V., Lenskaya, S.V., Samoilenko, N.D., Sobolev, V.S. 1966. Some physical properties of diamonds from Yakutian eclogite. Doklady Akademii Nauk SSSR. 168, 1151-1153.

Sobolev, N.V., Shatsky, V.S. 1990. Diamond inclusions in garnets from metamorphic rocks; a new environment for diamond formation. Nature. 343, 742746.

Spetsius, Z.V. 1999. Two generation of diamonds in eclogite xenoliths from Yakutiya In: Gurney, J.J., Gurney, L.G., Pascoe, M.D., Richardson, S.H (Eds.) Proceedings of the VIIth International Kimberlite Confertence. Cape Town. 2, 823-828.

Wirth, R., Rocholl, A. 2003. Nanocrystalline diamonds from the Earth's mantle underneaath Hawaii. Earth and Planetary Science Letters. 211, 357-362.

Xu, Sh., Okay, A.I., Ji, Sh., Sengor, A.M.C., Su, W. L., Yican, J.L.1992. Diamond from the Dabia Shan metamorphic rocks and its implication for tectonic setting. Science. $256,80-82$.

Acknowledgments The research was supported by the RF President Program on Leading Scientific Schools (grant N 1949.2008.5).

Correspondence and requests for materials should be addressed to S.K.S. (simakov@ap1250.spb.edu) 